\title{
OPEN Delineating colorectal cancer distribution, interaction, and risk prediction by environmental risk factors and serum trace elements
}

\begin{abstract}
Azmawati Mohammed Nawi ${ }^{1,2}$, Siok Fong Chin ${ }^{2}$, Luqman Mazlan ${ }^{3}$ \& Rahman Jamal $^{2 \bowtie}$
The burden of colorectal cancer (CRC) is increasing worldwide especially in developing countries. This phenomenon may be attributable to lifestyle, dietary and environmental risk factors. We aimed to determine the level of 25 trace elements, their interaction with environmental risk factors, and subsequently develop a risk prediction model for CRC (RPM CRC). For the discovery phase, we used a hospital-based case-control study (CRC and non-CRC patients) and in the validation phase we analysed pre-symptomatic samples of CRC patients from The Malaysian Cohort Biobank. Information on the environmental risk factors were obtained and level of 25 trace elements measured using the ICP-MS method. CRC patients had lower $\mathrm{Zn}$ and Se levels but higher $\mathrm{Li}, \mathrm{Be}, \mathrm{Al}, \mathrm{Co}, \mathrm{Cu}, \mathrm{As}, \mathrm{Cd}, \mathrm{Rb}$, $\mathrm{Ba}, \mathrm{Hg}, \mathrm{Tl}$, and $\mathrm{Pb}$ levels compared to non-CRC patients. The positive interaction between red meat intake $\geq 50 \mathrm{~g} /$ day and $\mathrm{Co} \geq 4.77 \mu \mathrm{g} / \mathrm{L}$ (AP $0.97 ; 95 \% \mathrm{Cl} 0.91,1.03$ ) doubled the risk of CRC. A panel of 24 trace elements can predict simultaneously and accurate of high, moderate, and low risk of CRC (accuracy $100 \%$, AUC 1.00). This study provides a new input on possible roles for various trace elements in CRC as well as using a panel of trace elements as a screening approach to CRC.
\end{abstract}

The incidence and mortality of colorectal cancer (CRC) vary widely from country to country ${ }^{1}$. The incidence and mortality rates are still increasing in low- and middle-income countries ${ }^{2}$, while developed countries such as the United States show a decreasing trend ${ }^{3}$. In Asia, environmental factors and the low public awareness of CRC screening within the different ethnicities and cultures may contribute to the increasing trend in incidence ${ }^{4}$. Among the screening tests for detecting CRC, colonoscopy has a sensitivity of more than $90 \%$, with an estimated $59 \%$ reduction in risk of death from $\mathrm{CRC}^{5}$. However, it is an invasive procedure and costly, especially in countries that do not provide free population screening. A blood-based marker, which would be relatively inexpensive to measure, could increase screening compliance and be cost-effective ${ }^{6}$.

In recent years, there has been great interest in the analysis of trace elements (TEs) for use as biomarkers due to the diverse roles that TEs play in the various biochemical and physiological processes. The levels of arsenic (As), copper $(\mathrm{Cu})$, cobalt $(\mathrm{Co})$, nickel $(\mathrm{Ni})$, Magnesium $(\mathrm{Mg})$ and lead $(\mathrm{Pb})$ have been reported to be high in several cancers and are believed to contribute to cancer development ${ }^{7-11}$. There are few studies looking at the multi-element approach and most of them have used the atomic absorption spectroscopy approach and not the ICPMS method. There is a need for a multi-element approach to analyse the various TEs in blood samples The levels of TEs in the human body vary according to different environmental exposures and are influenced by diet intake ${ }^{12,13}$, smoking status ${ }^{14}$, and obesity ${ }^{15}$.

Most risk prediction models (RPMs) for CRC use information on non-modifiable (i.e., age, sex) and modifiable environmental factors (i.e., lifestyle, clinical data) ${ }^{16}$. RPMs that use information on environmental factors with the inclusion of TE levels are lacking. An RPM that can identify high-risk groups would be helpful and cost-beneficial and enable the development of focused preventive strategies.

The objectives of this study were to: (i) determine, compare and classify TE levels among CRC cases and controls, (ii) determine the interaction between serum TEs and environmental factors, and (iii) develop and validate a CRC RPM using TE levels and environmental factors.

\footnotetext{
${ }^{1}$ Department of Community Health, Faculty of Medicine, UKM Medical Center, Universiti Kebangsaan Malaysia, Jalan Yaacob Latif, Bandar Tun Razak, 56000 Cheras, W. Persekutuan, Malaysia. ${ }^{2}$ Medical Molecular Biology Institute (UMBI), Universiti Kebangsaan Malaysia (UKM), Jalan Yaacob Latif, Bandar Tun Razak, 56000 Cheras, W. Persekutuan, Malaysia. ${ }^{3}$ Department of Surgery, UKM Medical Center, UKM, Cheras, Malaysia. ${ }^{\square}$ email: azmawati@ppukm.ukm.edu.my; rahmanj@ppukm.ukm.edu.my
} 

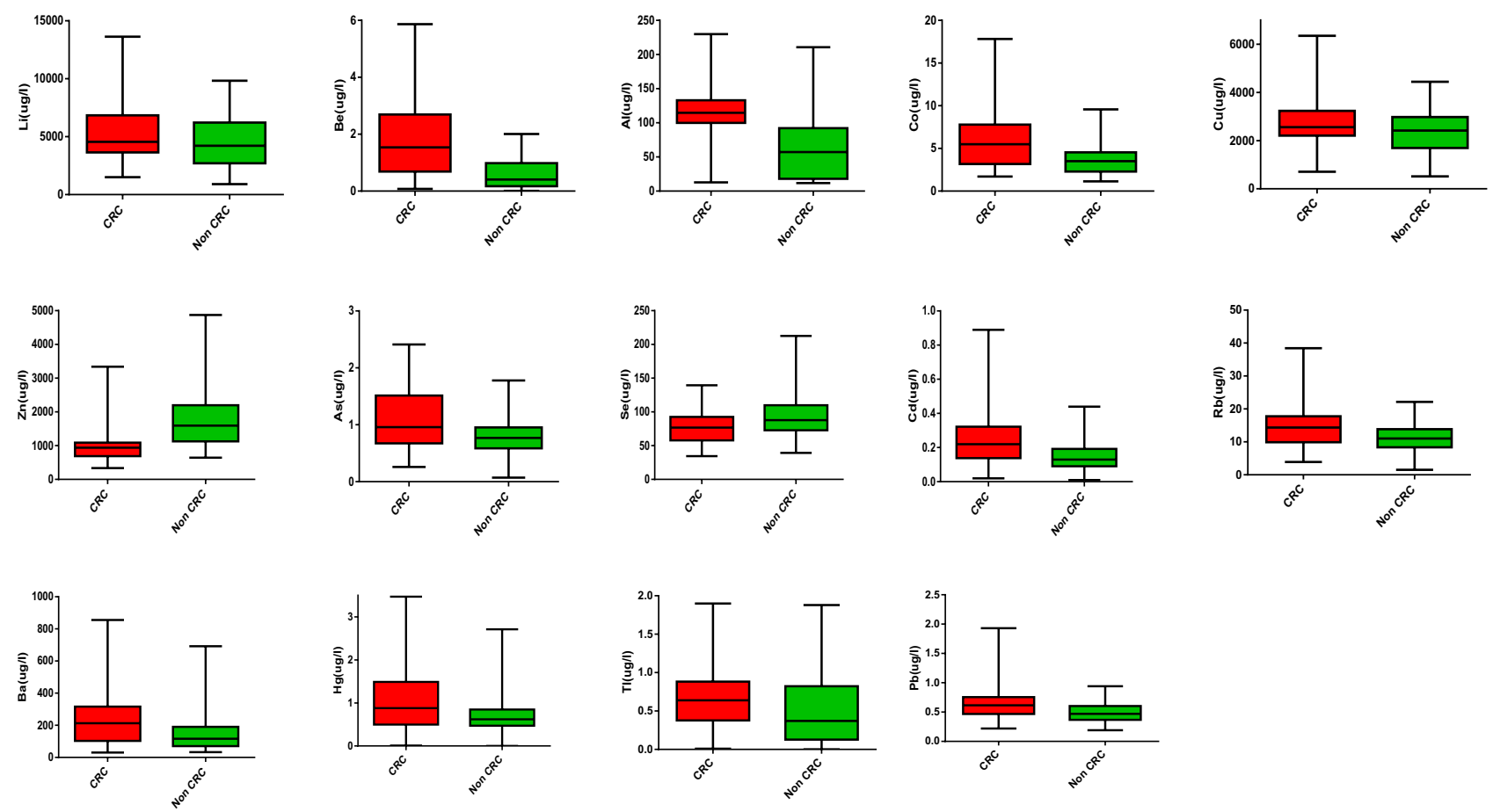

Figure 1. Selected 14 trace elements with significant difference concentration among CRC and non-CRC patients.

\section{Results}

Comparative analysis of environmental risk factors and serum TE levels between CRC and non-CRC patients. The environmental risk factors between the CRC and non-CRC samples were significantly different for sex, smoking status, physical activity, obesity, and between red meat and white meat intake. Most patients with CRC were men (61.8\%) while women outnumbered the men in those without CRC (52.9\%). Among the CRC patients, $48 \%$ were smokers, $66 \%$ were overweight and obese, $59.8 \%$ were physically inactive, $56.9 \%$ had higher red meat intake and 53.9\% had lower white meat intake. Fourteen TEs ( $\mathrm{Li}, \mathrm{Be}, \mathrm{Al}, \mathrm{Co}, \mathrm{Cu}$, $\mathrm{Zn}, \mathrm{As}, \mathrm{Se}, \mathrm{Cd}, \mathrm{Rb}, \mathrm{Ba}, \mathrm{Hg}, \mathrm{Tl}, \mathrm{Pb}$ ) showed significant mean/median differences between the patients with and without CRC. Patients with CRC had lower $\mathrm{Zn}$ and Se levels but higher $\mathrm{Li}, \mathrm{Be}, \mathrm{Al}, \mathrm{Co}, \mathrm{Cu}, \mathrm{As}, \mathrm{Cd}, \mathrm{Rb}, \mathrm{Ba}, \mathrm{Hg}, \mathrm{Tl}$, and $\mathrm{Pb}$ levels compared to patients without CRC (Fig. 1).

Linkage analysis of trace elements identifies disturbed clustering in colorectal cancer. Our results showed a clear alteration of the TE levels in CRC samples compared to non-CRC samples. The correlation between the 25 TEs were observed more in CRC patients (Table 1), with a clear clustering formed between CRC and non-CRC samples. The linkage analysis showed three clusters with a distance of 10-15 in the CRC group, and two clusters in the non-CRC group (Fig. 2). The essential TEs with antioxidant function, i.e., Se and Zn, clustered together in the non-CRC group but were in different clusters in the CRC group. PCA using 14 selected TEs clustered the CRC patients in a clear grouping compared to the non-CRC patients, and this clustering performed better than using the 25 TEs (Fig. 3). The variance for the 14 TEs improved to $56.3 \%$ for the three main components compared to the $40.8 \%$ from 25 TEs. However, it increased to $70.4 \%$ for the five main components compared to $54.1 \%$ for 25 TEs.

Serum TEs as biomarkers. The levels of the 14 significant TEs were analysed further to obtain the respective cut-off screening values for CRC (Table 2). The cut-off points obtained were compared with the values from the Agency for Toxic Substances and Disease Registry (ATSDR). From the comparison, only Be and As were within the normal range by the ATSDR but not the others. Most of the TE levels by the ATSDR were measured using AAS (atomic absorption spectrometry) and the reference values were derived from mainly the Western population. Only Be and $\mathrm{Zn}$ had AUC values $\geq 0.80$; therefore, the subsequent analysis for determining TEs as biomarkers used the ratio of $\mathrm{Be}$ and $\mathrm{Zn}$ with the other $12 \mathrm{TEs}$. The $\mathrm{Co} / \mathrm{Zn}$ ratio had the highest AUC, followed by the ratios of $\mathrm{Be} / \mathrm{Zn}(0.86)$ and $\mathrm{Rb} / \mathrm{Zn}(0.85)$ (Table 2).

The interaction between serum TE levels and environmental factors. CRC patients with red meat intake $\geq 50 \mathrm{~g} /$ day showed the highest contribution of risk due to interaction with $\mathrm{Co} \geq 4.77 \mu \mathrm{g} / \mathrm{L}$ followed by $\mathrm{Zn}<1103.06 \mu \mathrm{g} / \mathrm{L}$ and $\mathrm{Al} \geq 95.02 \mu \mathrm{g} / \mathrm{L}$. After controlling the confounder factors, the interactions contributed 97\% (Co), 95\% (Zn), and 88\% (Al) of CRC risk (Table 3). Only $\mathrm{Zn}<1103.06 \mu \mathrm{g} / \mathrm{L}$ with white meat intake $<50 \mathrm{~g} /$ 


\begin{tabular}{|c|c|c|c|c|}
\hline \multirow[b]{2}{*}{ Correlation } & \multicolumn{2}{|l|}{ CRC } & \multicolumn{2}{|c|}{ Non CRC } \\
\hline & r value & $p$ value & rvalue & $p$ value \\
\hline $\mathrm{Ba}-\mathrm{Ga}$ & 0.68 & $<0.001$ & 0.56 & $<0.001$ \\
\hline $\mathrm{Ag}-\mathrm{Ga}$ & 0.67 & $<0.001$ & 0.57 & $<0.001$ \\
\hline Ga-Mn & 0.61 & $<0.001$ & 0.72 & $<0.001$ \\
\hline $\mathrm{Ba}-\mathrm{Ag}$ & 0.58 & $<0.001$ & 0.61 & $<0.001$ \\
\hline $\mathrm{Ni}-\mathrm{Cr}$ & 0.57 & $<0.001$ & 0.65 & $<0.001$ \\
\hline $\mathrm{Ba}-\mathrm{Sr}$ & 0.57 & $<0.001$ & 0.60 & $<0.001$ \\
\hline $\mathrm{Mn}-\mathrm{Li}$ & 0.55 & $<0.001$ & 0.63 & $<0.001$ \\
\hline $\mathrm{U}-\mathrm{Ag}$ & 0.50 & $<0.001$ & 0.65 & $<0.001$ \\
\hline $\mathrm{Ba}-\mathrm{Cs}$ & 0.68 & $<0.001$ & \multicolumn{2}{|l|}{ NS } \\
\hline Cs-Ga & 0.68 & $<0.001$ & \multicolumn{2}{|l|}{ NS } \\
\hline $\mathrm{U}-\mathrm{Li}$ & 0.66 & $<0.001$ & \multicolumn{2}{|l|}{ NS } \\
\hline $\mathrm{Cs}-\mathrm{Ag}$ & 0.64 & $<0.001$ & \multicolumn{2}{|l|}{ NS } \\
\hline $\mathrm{Ba}-\mathrm{Mn}$ & 0.63 & $<0.001$ & \multicolumn{2}{|l|}{ NS } \\
\hline U-Ba & 0.62 & $<0.001$ & \multicolumn{2}{|l|}{ NS } \\
\hline $\mathrm{Ag}-\mathrm{Sr}$ & 0.61 & $<0.001$ & \multicolumn{2}{|l|}{ NS } \\
\hline Cs-Sr & 0.60 & $<0.001$ & \multicolumn{2}{|l|}{ NS } \\
\hline $\mathrm{Pb}-\mathrm{TI}$ & 0.60 & $<0.001$ & \multicolumn{2}{|l|}{ NS } \\
\hline $\mathrm{Pb}-\mathrm{Al}$ & 0.59 & $<0.001$ & \multicolumn{2}{|l|}{ NS } \\
\hline $\mathrm{Ba}-\mathrm{Li}$ & 0.59 & $<0.001$ & \multicolumn{2}{|l|}{ NS } \\
\hline $\mathrm{Sr}-\mathrm{Ga}$ & 0.58 & $<0.001$ & \multicolumn{2}{|l|}{ NS } \\
\hline $\mathrm{Ga}-\mathrm{Be}$ & 0.56 & $<0.001$ & \multicolumn{2}{|l|}{ NS } \\
\hline $\mathrm{Ag}-\mathrm{Be}$ & 0.56 & $<0.001$ & \multicolumn{2}{|l|}{ NS } \\
\hline $\mathrm{Mn}-\mathrm{Al}$ & 0.54 & $<0.001$ & \multicolumn{2}{|l|}{ NS } \\
\hline $\mathrm{Cs}-\mathrm{Be}$ & 0.53 & $<0.001$ & \multicolumn{2}{|l|}{ NS } \\
\hline Cs-Mn & 0.52 & $<0.001$ & \multicolumn{2}{|l|}{ NS } \\
\hline TI-Al & 0.52 & $<0.001$ & \multicolumn{2}{|l|}{ NS } \\
\hline $\mathrm{Cs}-\mathrm{V}$ & 0.52 & $<0.001$ & \multicolumn{2}{|l|}{ NS } \\
\hline $\mathrm{Pb}-\mathrm{C} 0$ & 0.52 & $<0.001$ & \multicolumn{2}{|l|}{ NS } \\
\hline $\mathrm{V}-\mathrm{Be}$ & 0.51 & $<0.001$ & NS & \\
\hline $\mathrm{U}-\mathrm{Ga}$ & 0.51 & $<0.001$ & NS & \\
\hline U-Mn & 0.51 & $<0.001$ & NS & \\
\hline $\mathrm{Ba}-\mathrm{Be}$ & 0.51 & $<0.001$ & NS & \\
\hline $\mathrm{U}-\mathrm{Sr}$ & 0.50 & $<0.001$ & NS & \\
\hline $\mathrm{Ag}-\mathrm{Mn}$ & 0.50 & $<0.001$ & NS & \\
\hline $\mathrm{V}-\mathrm{Al}$ & 0.50 & $<0.001$ & NS & \\
\hline $\mathrm{Ba}-\mathrm{Al}$ & NS & & 0.81 & $<0.001$ \\
\hline $\mathrm{Ni}-\mathrm{Al}$ & NS & & -0.67 & $<0.001$ \\
\hline Ga-Li & NS & & 0.64 & $<0.001$ \\
\hline $\mathrm{Cr}-\mathrm{Al}$ & NS & & -0.60 & $<0.001$ \\
\hline $\mathrm{Ba}-\mathrm{Ni}$ & NS & & -0.60 & $<0.001$ \\
\hline $\mathrm{Ag}-\mathrm{Al}$ & NS & & 0.56 & $<0.001$ \\
\hline $\mathrm{Ga}-\mathrm{Al}$ & NS & & 0.56 & $<0.001$ \\
\hline $\mathrm{Cr}-\mathrm{Mg}$ & NS & & 0.55 & $<0.001$ \\
\hline $\mathrm{Sr}-\mathrm{Mn}$ & NS & & 0.54 & $<0.001$ \\
\hline $\mathrm{Sr}-\mathrm{Rb}$ & NS & & 0.52 & $<0.001$ \\
\hline U-TI & NS & & 0.51 & $<0.001$ \\
\hline
\end{tabular}

Table 1. Comparison of trace elements correlation (correlation coefficient, $r \geq 0.5$ ) between CRC and nonCRC groups.

day showed positive interaction through multiplicative calculation in determining CRC risk, which was 39 times. The interaction between obesity with $\mathrm{Co} \geq 4.77 \mu \mathrm{g} / \mathrm{L}$ or $\mathrm{Zn}<1103.06 \mu \mathrm{g} / \mathrm{L}$ contributed to increased CRC risk of $88 \%$ and $65 \%$, respectively.

Development of Risk Prediction Model for CRC (CRC RPM). CRC RPM for high and low CRC risk. We used two datasets for developing the CRC RPM using TE levels, environmental risk factors, and the 
a)

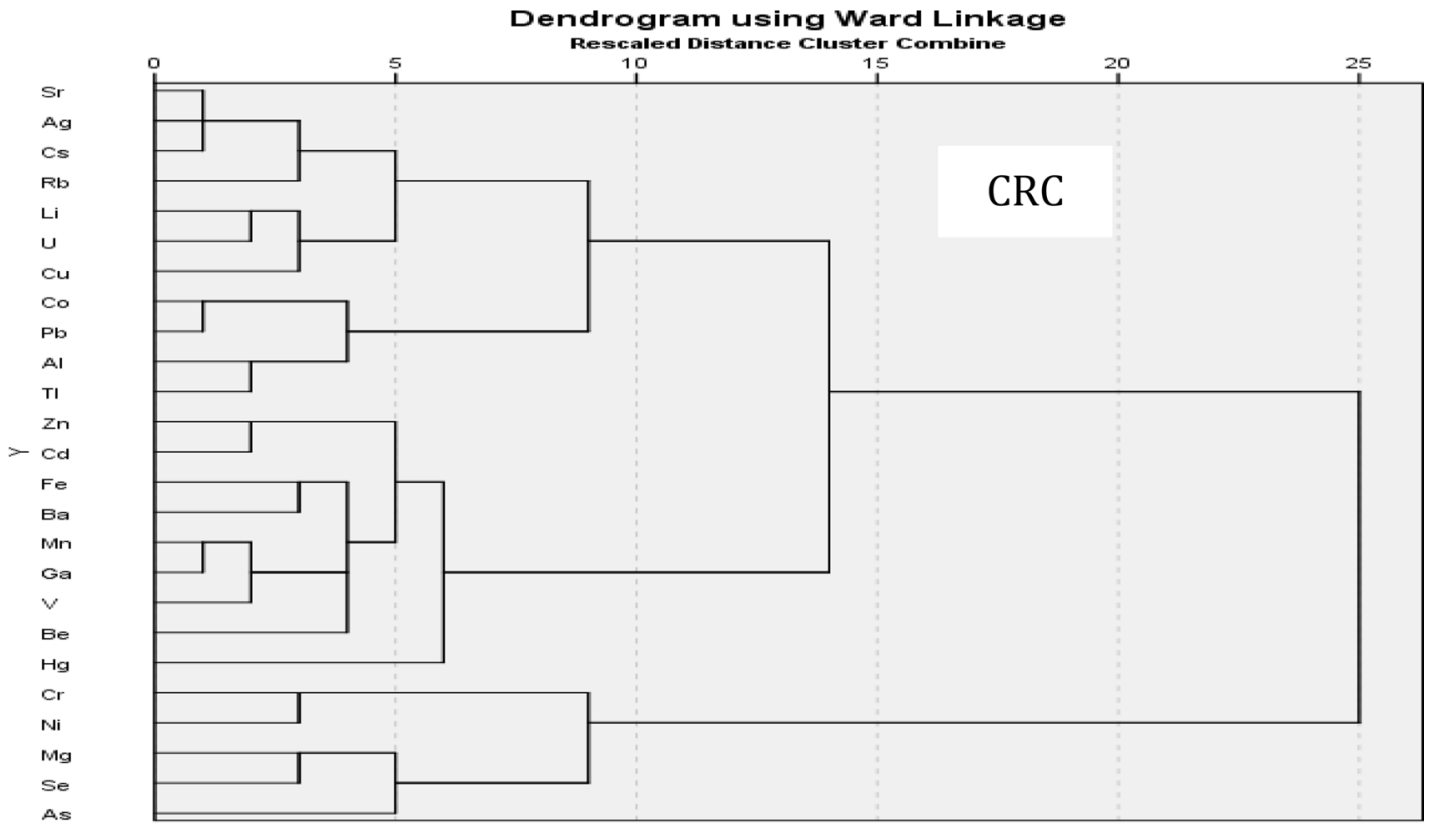

b)

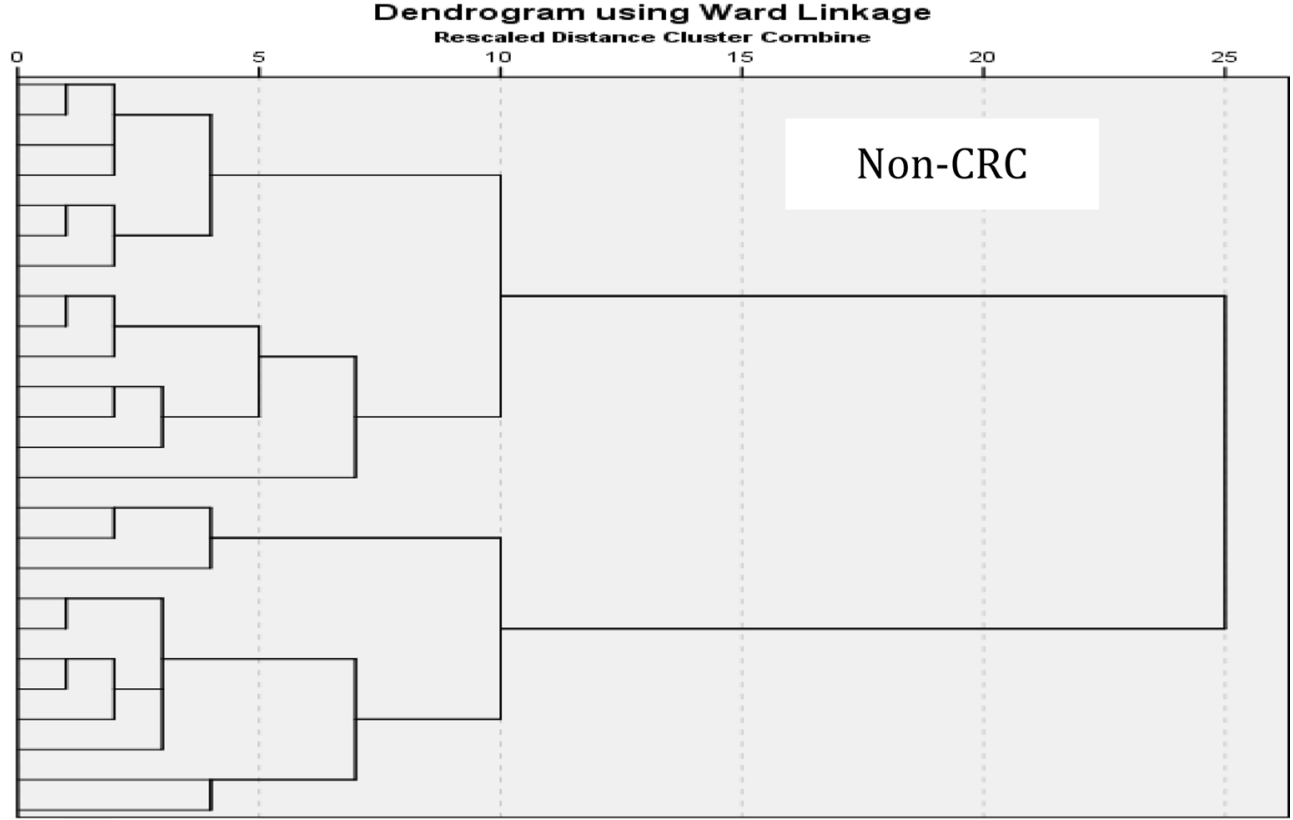

Figure 2. Dendogram using Ward Linkage for 25 trace elements. Different cluster patterns were observed among (a) CRC patients, (b) non-CRC patients.

TE-environmental risk factor combination (Table 4). The ANN algorithm analysis of the training data $(\mathrm{n}=159)$ yielded higher values for accuracy, sensitivity, specificity, PPV, and NPV for the CRC RPM using a panel of the 14 TEs. For CRC RPM using environmental risk factors, the SVM algorithm determined higher accuracy for the training data (83.0\%), followed by the results using the ANN algorithm (79.8\%). However, with the test data, the SVM and ANN algorithms determined $10 \%$ and $2 \%$ accuracy, respectively, for the CRC RPM. Therefore, the lower RMSE (root mean square error) value was required to select the best algorithm for the CRC RPM. The ANN algorithm determined a low RMSE value for the RPM using environmental risk factors. The best algorithm for the CRC RPM for the TE-environmental risk factor combination was LR. This model had the highest accuracy and AUC value compared to using the 14 TEs or environmental factors alone.

The CRC RPM was further tested with the ASX CRC cases and showed that the 14-TE panel (81.1\%) was the best model (Fig. 4). Although the RPM using the 14-TE panel yielded higher accuracy and AUC value, it was not specific. The RPM analysis showed that the 14-TE panel could predict CRC risk among the asymptomatic population.

CRC RPM for high, moderate, and low CRC risk. The CRC RPM developed in the discovery phase showed good accuracy in predicting high and low CRC risk. However, the accuracy decreased when tested with ASX CRC 
25 trace elements

a)

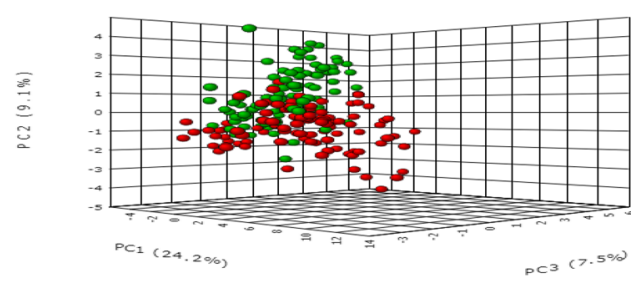

b)

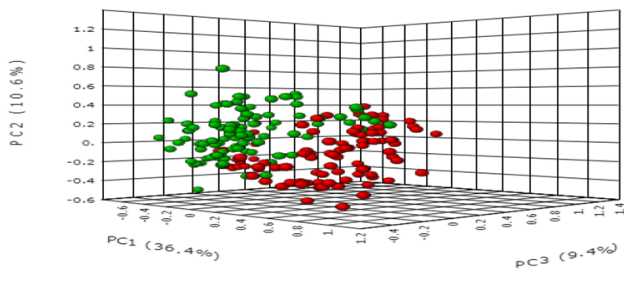

c)

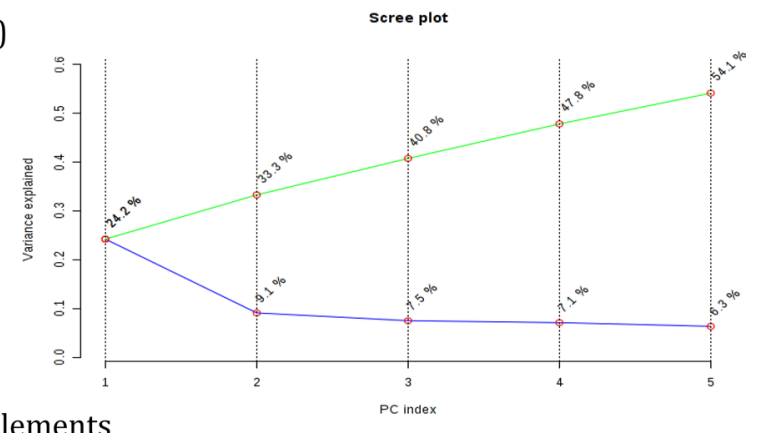

14 trace elements

Non-CRC

CRC

d)

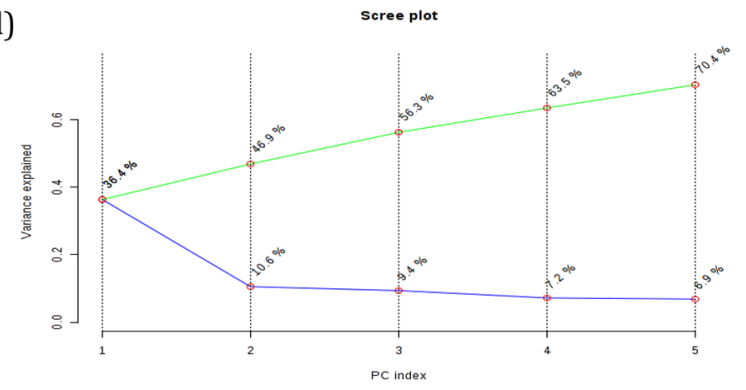

Figure 3. Trace elements distribution. (a) PCA showed a distribution of 25 trace elements in the CRC and non-CRC group in the adjacent cluster and can be distinguished by the three main components. (b) PCA shows a clear cluster for CRC and non-CRC group based on the distribution of 14 significant trace elements (c) Plot scree shows the variance explained with the three main components of the 25 trace elements is $40.8 \%$ while the addition to the five components can improve the explained of the variance to $54.1 \%$. (d) Plot scree shows the variance explained with the three main components of 14 trace elements is $56.3 \%$ while adding to five components can increase the variance explained to $70.4 \%$.

samples. This might have been because the data used in RPM development were from patients with CRC, hence reflecting a late stage pathology as compared to the asymptomatic stage. Therefore, the CRC RPM required improvement with the inclusion of data from ASX CRC itself. The improved CRC RPM could evaluate CRC risk simultaneously into three levels: high (CRC), moderate (ASX CRC), and low (non-CRC). Before the new CRC RPM was developed, selection of variables for the TEs and environmental risk factors was required that could differentiate the CRC, ASX CRC, and non-CRC groups. Only the selected variables were included in the CRC RPM development. The level of 24 TEs (Ag, Al, As, Ba, Be, Cd, Co, Cr, Cs, Cu, Ga, Li, Mg, Mn, Ni, Pb, Rb, Se, $\mathrm{Sr}, \mathrm{Tl}, \mathrm{U}, \mathrm{V}, \mathrm{Zn}, \mathrm{Hg}$ ) and eight environmental risk factors (age, ethnicity, comorbidities, smoking status, physical activity, obesity, red meat intake, white meat intake) were significantly different between the three groups and were included in model development.

The CRC RPM using the 24-TE panel produced the highest accuracy (100\%) after testing with the test data (Table 5). This was followed by the CRC RPM using the TE-environmental risk combination (86.5\%) and environmental risk factors alone $(67.3 \%)$. Besides that, the LR algorithm was selected for all three CRC RPMs, with the training data yielding high accuracy. Although the SVM algorithm yielded higher accuracy for the CRC RPM using environmental risk factors as compared to LR, the accuracy decreased by almost $25 \%$ for the SVM algorithm as compared to LR (7.1\%). Therefore, LR was selected for the CRC RPM using environmental risk factors.

CRC RPM accuracy was evaluated using the validation data $(n=69)$. The highest accuracy for the CRC RPM was based on the 24-TE panel (Fig. 5). The findings confirm the model's consistency in predicting CRC risk with good accuracy, sensitivity, specificity, PPV, NPV, and AUC value. It showed that the CRC RPM could perform accurate predictions using the 24-TE panel compared to RPMs using the TE-environmental risk factor combination or environmental risk factors alone. The CRC RPM was not only able to predict high CRC risk in individuals, but also among individuals with moderate CRC risk and who did not have any CRC symptoms.

\section{Discussion}

Determination, comparison, and classification of TE levels between CRC and non-CRC cases. In the present study, we identified a panel of $14 \mathrm{TEs}$ ( $\mathrm{Li}, \mathrm{Be}, \mathrm{Al}, \mathrm{Co}, \mathrm{Cu}, \mathrm{Zn}, \mathrm{As}, \mathrm{Se}, \mathrm{Cd}, \mathrm{Rb}, \mathrm{Ba}, \mathrm{Hg}, \mathrm{Tl}$, $\mathrm{Pb}$ ) that separated CRC from the non-CRC samples. We noted that 10 of the $14 \mathrm{TEs}(\mathrm{Li}, \mathrm{Be}, \mathrm{Al}, \mathrm{Co}, \mathrm{Rb}, \mathrm{Ba}, \mathrm{As}$, $\mathrm{Hg}, \mathrm{Tl}, \mathrm{Pb}$ ) have not been reported to be altered in patients with $\mathrm{CRC}$. Be, $\mathrm{Al}, \mathrm{Co}, \mathrm{Rb}, \mathrm{Ba}, \mathrm{As}, \mathrm{Hg}$ and $\mathrm{Pb}$ have been reported for other cancer types, but not for $\mathrm{CRC}^{17-24}$. High or low levels of TEs can possibly contribute to $\mathrm{CRC}$ through various mechanisms. Among the mechanisms that have been reported is inhibition of DNA repair, inhibition of DNA methylation, increased oxidative stress, and altered gene expression ${ }^{25}$. 


\begin{tabular}{|l|l|l|l|l|l|}
\hline Trace elements & $\begin{array}{l}\text { Suggested cut off value } \\
\text { (ug/ })\end{array}$ & AUC $(\mathbf{9 5 C I})$ & $\boldsymbol{p}$ value & $\begin{array}{l}\text { Reported normal range } \\
(\mathbf{u g} / \mathbf{L})\end{array}$ & Reference \\
\hline $\mathrm{Li}$ & 3633.62 & $0.60(0.52-0.68)$ & 0.016 & NA & NA \\
\hline $\mathrm{Be}$ & 0.93 & $0.80(0.75-0.86)^{*}$ & $<0.001$ & $0.28-1.00$ & ATSDR 2002 \\
\hline $\mathrm{Al}$ & 95.02 & $0.73(0.65-0.80)$ & $<0.001$ & $1.00-3.00$ & ATSDR 2011 \\
\hline $\mathrm{Co}$ & 4.77 & $0.72(0.65-0.79)$ & $<0.001$ & $5.70-7.90$ & ATSDR 2004 \\
\hline $\mathrm{Cu}$ & 1892.77 & $0.59(0.51-0.67)$ & 0.026 & $2390.00-3460.00$ & ATSDR 2004 \\
\hline $\mathrm{Zn}$ & 1103.06 & $0.83(0.77-0.89)^{*}$ & $<0.001$ & 1000 & ATSDR 2005 \\
\hline $\mathrm{As}$ & 0.94 & $0.64(0.60-0.72)$ & $<0.001$ & $<1.00$ & ATSDR 2007 \\
\hline $\mathrm{Se}$ & 81.74 & $0.66(0.58-0.73)$ & $<0.001$ & 125 & ATSDR 2003 \\
\hline $\mathrm{Rb}$ & 12.63 & $0.67(0.60-0.74)$ & $<0.001$ & NA & NA \\
\hline $\mathrm{Cd}$ & 0.19 & $0.71(0.64-0.78)$ & $<0.001$ & 0.31 & ATSDR 2012 \\
\hline $\mathrm{Ba}$ & 151.03 & $0.66(0.58-0.73)$ & $<0.001$ & NA & NA \\
\hline $\mathrm{Hg}$ & 0.76 & $0.62(0.54-0.70)$ & 0.003 & 0.5 & ASTDR 1999 \\
\hline $\mathrm{TI}$ & 0.41 & $0.63(0.56-0.71)$ & 0.001 & NA & NA \\
\hline $\mathrm{Pb}$ & 0.53 & $0.65(0.58-0.73)$ & $<0.001$ & 15 & ASTDR 2007 \\
\hline $\mathrm{Single} /$ ratio trace elements & $\mathrm{AUC}(\mathbf{9 5 C I})$ & $\mathrm{Sensitivity}$ & Specificity & PPV & NPV \\
\hline $\mathrm{Co} / \mathrm{Zn}$ & $0.87(0.82-0.92)$ & 79.4 & 76.5 & 75.9 & 79.1 \\
\hline $\mathrm{Be} / \mathrm{Zn}$ & $0.86(0.81-0.91)$ & 77.5 & 75.5 & 75.2 & 76.8 \\
\hline $\mathrm{Rb} / \mathrm{Zn}$ & $0.85(0.80-0.90)$ & 76.5 & 73.5 & 74.8 & 79.6 \\
\hline $\mathrm{Cd} / \mathrm{Zn}$ & $0.84(0.78-0.90)$ & 79.4 & 76.5 & 70 & 83.1 \\
\hline $\mathrm{Zn}$ & $0.83(0.77-0.89)$ & 80.4 & 77.5 & 79.8 & 78.1 \\
\hline $\mathrm{Cu} / \mathrm{Zn}$ & $0.83(0.77-0.88)$ & 76.5 & 73.5 & 74.3 & 75.8 \\
\hline $\mathrm{Pb} / \mathrm{Zn}$ & $0.83(0.77-0.88)$ & 77.5 & 74.5 & 75 & 74 \\
\hline $\mathrm{As} / \mathrm{Zn}$ & $0.81(0.76-0.86)$ & 77.5 & 74.5 & 75 & 76.5 \\
\hline $\mathrm{Al} / \mathrm{Zn}$ & $0.80(0.74-0.86)$ & 77.5 & 74.5 & 75.2 & 77 \\
\hline $\mathrm{Be}$ & $0.80(0.75-0.86)$ & 67.6 & 77.5 & 75 & \\
\hline & & & & & \\
\hline
\end{tabular}

Table 2. Evaluation of single/ratio trace elements as a biomarker for CRC and comparison with the reported normal range. $A U C$ area under curve, $P P V$ positive predictive value, $N P V$ negative predictive value.

\begin{tabular}{|c|c|c|c|c|c|c|c|c|c|c|c|c|c|}
\hline \multirow{2}{*}{$\begin{array}{l}\text { Trace } \\
\text { elements }\end{array}$} & \multirow{2}{*}{$\begin{array}{l}\begin{array}{l}\text { Red meat } \\
\text { intake }\end{array} \\
\text { (g/day) }\end{array}$} & \multirow{2}{*}{$\begin{array}{l}\text { CRC } \\
n\end{array}$} & \multirow{2}{*}{$\begin{array}{l}\text { Non-CRC } \\
\mathbf{n}\end{array}$} & \multicolumn{5}{|c|}{ Univariate $^{\mathrm{a}}$} & \multicolumn{5}{|c|}{ Adjusted $^{\mathrm{b}}$} \\
\hline & & & & OR & $(95 \% \mathrm{CI})$ & Interaction & ORINT & $\begin{array}{l}\text { ORINT } \\
95 \% \mathrm{CI}\end{array}$ & OR & $95 \% \mathrm{CI}$ & Interaction & ORINT & $\begin{array}{l}\text { ORINT } \\
95 \% \mathrm{CI}\end{array}$ \\
\hline $\mathrm{Zn} \geq 1103.06$ & - & 6 & 66 & 1 & & $\begin{array}{l}\text { Multiplica- } \\
\text { tive }\end{array}$ & 5.49 & $(3.48,8.65)$ & 1 & & $\begin{array}{l}\text { Multiplica- } \\
\text { tive }\end{array}$ & 0.53 & $(0.04,7.34)$ \\
\hline $\mathrm{Zn}<1103.06$ & - & 22 & 16 & 15.13 & $(5.27,43.44)$ & RERI & 0.27 & $(0.03,0.50)$ & 25.87 & $\begin{array}{l}4.49, \\
149.10)\end{array}$ & RERI & 0.22 & $(-0.13,0.57)$ \\
\hline $\mathrm{Zn} \geq 1103.06$ & + & 18 & 16 & 12.37 & $(4.23,36.19)$ & \multirow{2}{*}{$\mathrm{AP}$} & \multirow{2}{*}{0.92} & \multirow{2}{*}{$(0.83,1.01)$} & 16.8 & $\begin{array}{l}(1.02, \\
102.89)\end{array}$ & \multirow{2}{*}{$\mathrm{AP}$} & \multirow{2}{*}{0.95} & \multirow{2}{*}{$(0.89,1.03)$} \\
\hline $\mathrm{Zn}<1103.06$ & + & 56 & 4 & 154 & $\begin{array}{l}\text { (41.37, } \\
573.21)\end{array}$ & & & & 150.35 & $\begin{array}{l}(5.51, \\
4103.67)\end{array}$ & & & \\
\hline $\mathrm{Co}<4.77$ & - & 14 & 68 & 1 & & $\begin{array}{l}\text { Multiplica- } \\
\text { tive }\end{array}$ & 5.6 & $(3.45,9.09)$ & 1 & & $\begin{array}{l}\text { Multiplica- } \\
\text { tive }\end{array}$ & 0.72 & $(0.04,12.16)$ \\
\hline $\mathrm{Co} \geq 4.77$ & - & 14 & 14 & 4.86 & $(1.90,12.41)$ & RERI & 0.49 & $(0.06,0.92)$ & 8.63 & $(1.58,47.09)$ & RERI & 0.52 & $(-0.42,1.46)$ \\
\hline $\mathrm{Co}<4.77$ & + & 29 & 16 & 8.8 & $(3.81,20.36)$ & \multirow{2}{*}{$\mathrm{AP}$} & \multirow{2}{*}{0.89} & \multirow{2}{*}{$(0.79,0.98)$} & 25.93 & $\begin{array}{l}(2.21, \\
303.90) \\
\end{array}$ & \multirow{2}{*}{$\mathrm{AP}$} & \multirow{2}{*}{0.97} & \multirow{2}{*}{$(0.91,1.03)$} \\
\hline $\mathrm{Co} \geq 4.77$ & + & 45 & 4 & 54.64 & $\begin{array}{l}\text { (16.90, } \\
176.64)\end{array}$ & & & & 55.5 & $\begin{array}{l}(3.98, \\
773.62)\end{array}$ & & & \\
\hline $\mathrm{Al}<95.02$ & - & 6 & 60 & 1 & & $\begin{array}{l}\text { Multiplica- } \\
\text { tive }\end{array}$ & 6.6 & $(4.01,10.83)$ & 1 & & $\begin{array}{l}\text { Multiplica- } \\
\text { tive }\end{array}$ & 72.76 & $\begin{array}{l}0.55 \\
9673.37) \\
\end{array}$ \\
\hline $\mathrm{Al} \geq 95.02$ & - & 22 & 22 & 10 & $(3.58,27.91)$ & RERI & 0.25 & $(0.03,0.47)$ & 10.69 & $(1.73,66.13)$ & RERI & 0.21 & $(-0.11,0.53)$ \\
\hline $\mathrm{Al}<95.02$ & + & 18 & 19 & 9.47 & $(3.29,27.30)$ & \multirow{2}{*}{$\mathrm{AP}$} & \multirow{2}{*}{0.89} & \multirow{2}{*}{$(0.78,1.01)$} & 28.34 & $\begin{array}{l}1.50, \\
536.77)\end{array}$ & \multirow{2}{*}{ AP } & \multirow{2}{*}{0.88} & \multirow{2}{*}{$(0.68,1.09)$} \\
\hline $\mathrm{Al} \geq 95.02$ & + & 56 & 1 & 560 & $\begin{array}{l}(65.35, \\
4798.38)\end{array}$ & & & & 32.97 & $\begin{array}{l}(1.93, \\
562.08)\end{array}$ & & & \\
\hline
\end{tabular}

Table 3. Interaction analysis between red meat intake with $\mathrm{Zn}$, Co and $\mathrm{Al}$ levels. OR odds ratio, ORINT odds ratio due to interaction. ${ }^{\mathrm{a} N o t}$ adjusted to other factors, ${ }^{\mathrm{b}}$ Adjusted to all environmental risk factors. 


\begin{tabular}{|c|c|c|c|c|c|c|c|c|c|c|c|c|c|c|c|c|c|c|}
\hline \multirow{3}{*}{$\begin{array}{l}\text { Evaluation } \\
\text { criteria }\end{array}$} & \multicolumn{6}{|c|}{ Trace element-based } & \multicolumn{6}{|c|}{ Environmental factor-based } & \multicolumn{6}{|c|}{$\begin{array}{l}\text { Trace element-based \& environmental factor- } \\
\text { based }\end{array}$} \\
\hline & \multicolumn{3}{|c|}{$\begin{array}{l}\text { Training data } \\
(\mathbf{n}=159)\end{array}$} & \multicolumn{3}{|c|}{ Test data $(n=40)$} & \multicolumn{3}{|c|}{$\begin{array}{l}\text { Training data } \\
(\mathbf{n}=159)\end{array}$} & \multicolumn{3}{|c|}{ Test data $(n=40)$} & \multicolumn{3}{|c|}{ Training data $(n=159)$} & \multicolumn{3}{|c|}{ Test data $(n=40)$} \\
\hline & SVM & ANN & LR & SVM & ANN & LR & SVM & ANN & LR & SVM & ANN & LR & SVM & ANN & LR & SVM & ANN & LR \\
\hline $\begin{array}{l}\text { Correctly clas- } \\
\text { sified }\end{array}$ & 146 & 157 & 147 & 39 & 37 & 37 & 132 & 127 & 126 & 29 & 31 & 30 & 155 & 157 & 159 & 39 & 38 & 39 \\
\hline $\begin{array}{l}\text { Incorrectly clas- } \\
\text { sified }\end{array}$ & 13 & 2 & 12 & 1 & 3 & 3 & 27 & 32 & 33 & 11 & 9 & 10 & 4 & 2 & 0 & 1 & 2 & 1 \\
\hline Accuracy (\%) & 91.8 & 98.7 & 92.5 & 97.5 & 92.5 & 92.5 & 83.0 & 79.8 & 79.3 & 72.5 & 77.5 & 75.0 & 97.5 & 98.7 & 100.0 & 97.5 & 95.0 & 97.5 \\
\hline Sensitivity & 0.89 & 0.99 & 0.92 & 1.00 & 0.95 & 1.00 & 0.85 & 0.83 & 0.81 & 0.85 & 0.79 & 0.81 & 1.00 & 0.98 & 1.00 & 1.00 & 0.91 & 0.95 \\
\hline Specificity & 0.94 & 0.99 & 0.93 & 0.95 & 0.90 & 0.87 & 0.81 & 0.77 & 0.78 & 0.67 & 0.76 & 0.71 & 0.95 & 1.00 & 1.00 & 0.95 & 1.00 & 1.00 \\
\hline PPV & 0.95 & 0.99 & 0.94 & 0.95 & 0.90 & 0.85 & 0.82 & 0.77 & 0.78 & 0.55 & 0.75 & 0.65 & 0.95 & 1.00 & 1.00 & 0.95 & 1.00 & 1.00 \\
\hline NPV & 0.88 & 0.99 & 0.91 & 1.00 & 0.95 & 1.00 & 0.84 & 0.83 & 0.81 & 0.90 & 0.80 & 0.85 & 1.00 & 0.97 & 1.00 & 1.00 & 0.90 & 0.95 \\
\hline Variable & 14 & 14 & 14 & 14 & 14 & 14 & 6 & 6 & 6 & 6 & 6 & 6 & 20 & 20 & 20 & 20 & 20 & 20 \\
\hline Kappa Statistic & 0.84 & 0.97 & 0.85 & 0.95 & 0.85 & 0.85 & 0.66 & 0.60 & 0.59 & 0.45 & 0.55 & 0.50 & 0.95 & 0.97 & 1.00 & 0.95 & 0.90 & 0.95 \\
\hline RMSE & NA & NA & NA & 0.0045 & 0.0034 & 0.0046 & NA & NA & NA & 0.0041 & 0.0039 & 0.0039 & NA & NA & NA & 0.005 & 0.0047 & 0.0035 \\
\hline AUC & 0.98 & 0.99 & 0.98 & 1.00 & 0.98 & 0.99 & 0.90 & 0.84 & 0.87 & 0.78 & 0.87 & 0.88 & 0.99 & 1.00 & 1.00 & 1.00 & 1.00 & 0.99 \\
\hline
\end{tabular}

Table 4. Development of CRC RPM (high and low risk) using trace element, environmental risk factors and a combination of trace element-environmental risk factors. SVM support vector machine, $A N N$ artificial neural network, $L R$ logistic regression, $R M S E$ root mean square error, $P P V$ positive predictive value, $N P V$ negative predictive value.

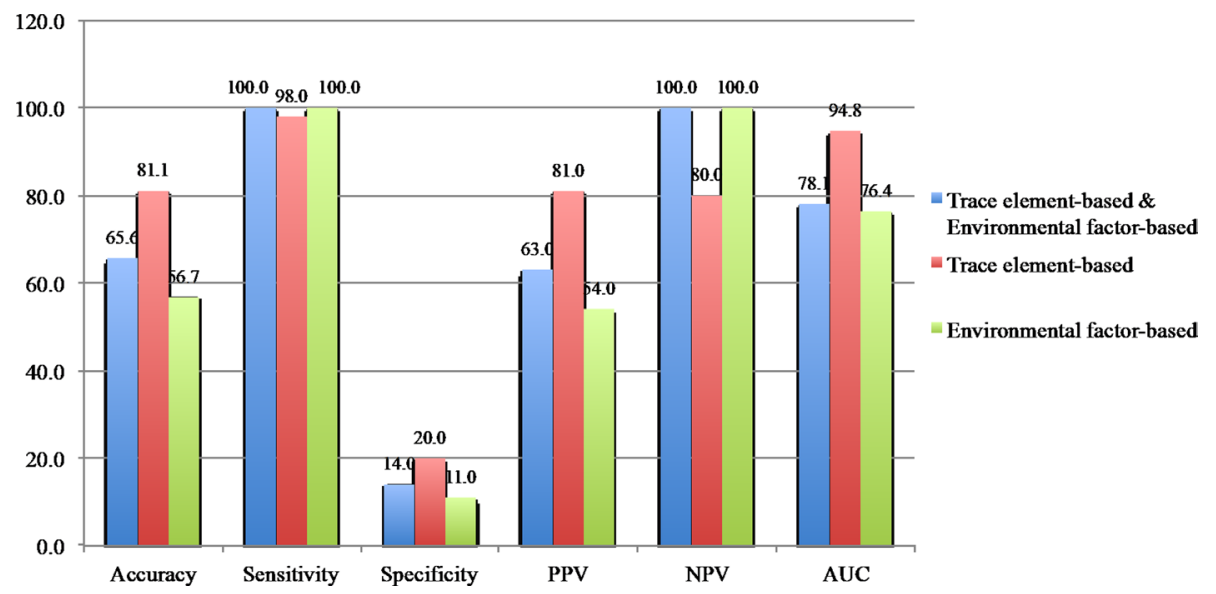

Figure 4. Validation of CRC RPM among ASX CRC $(n=90)$.

We found that the levels of Se, $\mathrm{Zn}$, and $\mathrm{Cd}$ are in concordance with the results of a previous study on patients with $\mathrm{CRC}^{26-28}$. The low levels of Se and $\mathrm{Zn}$ we found in the patients with CRC have also been reported previously. It is believed that Se acts through an antioxidant defence system to reduce oxidative stress and minimise DNA damage $^{29}$. Similar to $\mathrm{Se}, \mathrm{Zn}$ is an important co-factor in antioxidant enzymes (superoxide dismutase [SOD], $\mathrm{GPx}$ ) and is involved in the defence systems of the body ${ }^{30}$. In vivo and in vitro studies have proven that $\mathrm{Zn}$ can prevent cancer development through apoptosis mechanisms ${ }^{31}$. High Cd levels in serum ${ }^{32}$ and tissue ${ }^{33}$ have also been reported in patients with CRC. Cd is also a heavy metal and has been categorised as a human carcinogen ${ }^{34}$. The mechanisms involved in CRC formation are through oncogene activation and the inhibition of apoptosis ${ }^{35}$.

For $\mathrm{Cu}$, our findings were inconsistent when compared to previous studies. We found that patients with CRC had high $\mathrm{Cu}$ levels, but Milde et al. ${ }^{36}$ found that such patients had low $\mathrm{Cu}$ levels. The difference may be due to sample size, where Milde et al. studied only 20 patients, while our study involved 102 patients. Other researchers have reported similar findings to ours, where CRC patients with Dukes' stage C and D had higher Cu levels ${ }^{37}$. In the present study, most patients with CRC were diagnosed at Dukes' stage C. This indirectly explains why the patients with CRC in the present study had high Cu levels compared to the patients without CRC. Khoshdel et al. ${ }^{38}$ reported the same finding in a large sample of patients with CRC from Iran $(n=119)$, but unlike the present study using ICPMS, they used AAS. Therefore, the difference in Cu level findings in patients with CRC should be investigated further in a different and larger cohort of samples.

We found that there was more correlation between TEs and CRC than with non-CRC cases. Ba, Cs, Ga, U, $\mathrm{Li}, \mathrm{Ag}, \mathrm{Mn}, \mathrm{U}, \mathrm{Sr}, \mathrm{Pb}, \mathrm{Tl}, \mathrm{Sr}, \mathrm{Be}, \mathrm{Al}, \mathrm{V}$, and Co had positive correlation values $>0.5$. These TEs were all present in high quantities in the patients with CRC compared to the values recommended by the accredited ATSDR. When 


\begin{tabular}{|c|c|c|c|c|c|c|c|c|c|c|c|c|c|c|c|c|c|c|}
\hline \multirow{3}{*}{$\begin{array}{l}\text { Evaluation } \\
\text { Criteria }\end{array}$} & \multicolumn{6}{|c|}{ Trace element-based } & \multicolumn{6}{|c|}{ Environmental factor-based } & \multicolumn{6}{|c|}{$\begin{array}{l}\text { Trace element-based \& Environmental factor- } \\
\text { based }\end{array}$} \\
\hline & \multicolumn{3}{|c|}{ Training data $(n=168)$} & \multicolumn{3}{|c|}{ Test data $(n=52)$} & \multicolumn{3}{|c|}{ Training data $(n=168)$} & \multicolumn{3}{|c|}{ Test data $(n=52)$} & \multicolumn{3}{|c|}{ Training data $(n=168)$} & \multicolumn{3}{|c|}{ Test data $(n=52)$} \\
\hline & SVM & ANN & LR & SVM & ANN & LR & SVM & ANN & LR & SVM & ANN & LR & SVM & ANN & LR & SVM & ANN & LR \\
\hline Correctly classified & 161 & 141 & 168 & 46 & 39 & 47 & 142 & 110 & 125 & 31 & 32 & 35 & 168 & 157 & 168 & 42 & 45 & 45 \\
\hline $\begin{array}{l}\text { Incorrectly clas- } \\
\text { sified }\end{array}$ & 7 & 27 & 0 & 6 & 13 & 5 & 26 & 58 & 43 & 21 & 20 & 17 & 0 & 11 & 0 & 10 & 7 & 7 \\
\hline Accuracy (\%) & 95.8 & 84.0 & 100.0 & 88.5 & 75.0 & 100.0 & 84.5 & 65.5 & 74.4 & 59.6 & 61.5 & 67.3 & 100.0 & 93.5 & 100.0 & 80.8 & 86.5 & 86.5 \\
\hline \multicolumn{19}{|l|}{ High risk (CRC) } \\
\hline Sensitivity & 0.97 & 0.82 & 1.00 & 0.85 & 0.70 & 1.00 & 0.84 & 0.70 & 0.69 & 0.50 & 0.65 & 0.65 & 1.00 & 1.00 & 1.00 & 0.75 & 1.00 & 0.85 \\
\hline Specificity & 0.97 & 0.89 & 1.00 & 0.94 & 0.81 & 1.00 & 0.93 & 0.71 & 0.86 & 0.78 & 0.72 & 0.78 & 1.00 & 0.94 & 1.00 & 0.88 & 0.81 & 0.91 \\
\hline PPV & 0.95 & 0.81 & 1.00 & 0.89 & 0.70 & 1.00 & 0.86 & 0.58 & 0.74 & 0.59 & 0.59 & 0.65 & 1.00 & 0.90 & 1.00 & 0.79 & 0.77 & 0.85 \\
\hline NPV & 0.98 & 0.90 & 1.00 & 0.91 & 0.81 & 1.00 & 0.91 & 0.81 & 0.83 & 0.71 & 0.77 & 0.78 & 1.00 & 1.00 & 1.00 & 0.85 & 1.00 & 0.91 \\
\hline \multicolumn{19}{|c|}{ Moderate risk (ASX CRC) } \\
\hline Sensitivity & 0.98 & 0.92 & 1.00 & 1.00 & 0.04 & 1.00 & 0.88 & 0.59 & 0.82 & 0.64 & 0.45 & 0.73 & 1.00 & 0.86 & 1.00 & 1.00 & 0.82 & 0.91 \\
\hline Specificity & 0.97 & 0.97 & 1.00 & 0.98 & 0.72 & 1.00 & 0.93 & 0.94 & 0.91 & 0.88 & 0.90 & 0.90 & 1.00 & 1.00 & 1.00 & 0.93 & 1.00 & 0.98 \\
\hline PPV & 0.93 & 0.92 & 1.00 & 0.92 & 0.04 & 1.00 & 0.85 & 0.81 & 0.81 & 0.58 & 0.56 & 0.67 & 1.00 & 1.00 & 1.00 & 0.79 & 1.00 & 0.91 \\
\hline NPV & 0.99 & 0.97 & 1.00 & 1.00 & 0.67 & 1.00 & 0.95 & 0.84 & 0.92 & 0.90 & 0.86 & 0.93 & 1.00 & 0.94 & 1.00 & 1.00 & 0.95 & 0.98 \\
\hline Variable & 24 & 24 & 24 & 24 & 24 & 24 & 8 & 8 & 8 & 8 & 8 & 8 & 32 & 32 & 32 & 32 & 32 & 32 \\
\hline Kappa Statistic & 0.94 & 0.76 & 1.00 & 0.82 & 0.61 & 0.85 & 0.77 & 0.48 & 0.62 & 0.38 & 0.40 & 0.50 & 1.00 & 0.90 & 1.00 & 0.71 & 0.79 & 0.79 \\
\hline AUC & 0.98 & 0.99 & 1.00 & 0.99 & 0.86 & 1.00 & 0.88 & 0.88 & 0.90 & 0.86 & 0.77 & 0.83 & 1.00 & 0.97 & 1.00 & 0.88 & 0.88 & 0.94 \\
\hline
\end{tabular}

Table 5. Development of CRC RPM (high, moderate and low risk) using trace element, environmental risk factors and a combination of trace element-environmental risk factors. SVM support vector machine, ANN artificial neural network, $L R$ logistic regression, $R M S E$ root mean square error, $P P V$ positive predictive value, $N P V$ negative predictive value.

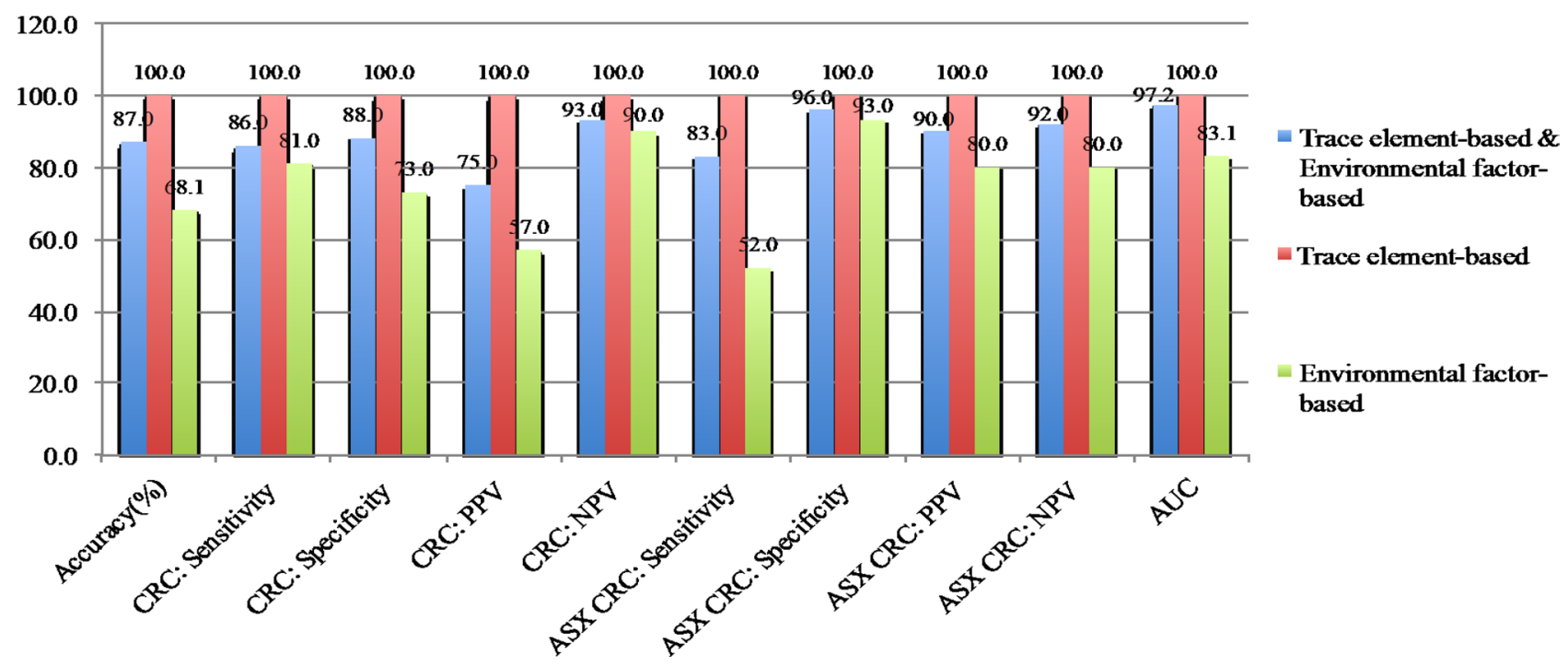

Figure 5. Validation of CRC RPM using validation data $(n=69)$.

there is a correlation between TEs, especially at high levels, it is likely to have a toxic effect on the human body and thus could lead to CRC formation ${ }^{39}$.

Patients with CRC also have disrupted TE distribution, especially for essential TEs such as Cu, Zn, and Se. These TEs were grouped into different clusters in patients with CRC patients compared to non-CRC cases. Feng et al. ${ }^{40}$ studied patients with breast cancer and found that these three TEs are closely related to the status of oxidative stresses that can contribute to cancer formation. There are few findings on the correlation between TEs and their distribution patterns in CRC. However, there is a significant relationship between the TEs and their distribution in patients with CRC as compared to patients without CRC.

Biomarkers using TEs attracted more attention following the reporting of evidence from previous studies on TEs and disease risk $^{41}$. TEs have been used for differentiating to patients with and without cancer such as in breast cancer ${ }^{42}$, lung cancer ${ }^{43}$, prostate cancer $^{44}$, and $\mathrm{CRC}^{45}$. Although TEs have attracted a lot of attention as potential cancer biomarkers, the cut-off values of the respective TEs have not been determined. Reference sources remain scarce, and the normal level values are typically referred through the ATSDR website (https:// www.atsdr.cdc.gov/). The TE values on the ATSDR website are more relevant to the general population rather 
than to respective diseases including cancers. Moreover, the reference values were established in the last decade based on the Western population. Therefore, a screening cut-off value for patients with CRC itself is much needed to be used for identifying those with high CRC risk. Our findings cut off value for differenting CRC population almost similar with ATSDR value for Be and $\mathrm{Zn}$.

In the present study, though the level of 14 TEs could differentiate CRC and non-CRC samples, only Be and $\mathrm{Zn}$ levels had AUC value of $\geq 0.8$. The cut-off values for $\mathrm{Be}$ and $\mathrm{Zn}$ which we have proposed are in the range set by the ATSDR in the general population ${ }^{46,47}$. For the other 12 TEs the AUC values were $<0.8$ hence they are less useful as individual biomarkers ${ }^{48}$. Therefore, the cut-off values for Be and $\mathrm{Zn}$ we have proposed can be used as reference or screening values for patients with CRC. The cut-off values from this findings may varies with different population but our finding cut off value are in line with ATSDR suggestion in differentiating CRC and non-CRC.

Apart from the individual TE, it has also been suggested that TE ratios can be used as biomarkers. We found that the AUC value can be improved through the use of the TE ratio rather than a single TE. In the present study, the Co/Zn ratio yielded the highest AUC value. However, no study to date has assessed Co or even the $\mathrm{Co} / \mathrm{Zn}$ ratio as a biological marker for CRC. However, it has been suggested that the $\mathrm{Cu} / \mathrm{Zn}$ ratio be used as a biomarker, but no AUC or sensitivity values have been specified for the ratio ${ }^{37}$. Although previous studies have focused on the $\mathrm{Cu} / \mathrm{Zn}$ ratio, our findings on the $\mathrm{Co} / \mathrm{Zn}$ ratio require further validation of its potential use as a CRC screening test.

The interaction between serum TEs and environmental factors. We also showed that the interaction between excessive red meat intake with low $\mathrm{Zn}$ levels could increase CRC risk. Red meat is a rich source of $\mathrm{Zn}^{49}$. Excessive red meat intake increases $\mathrm{Zn}$ levels, but its bioavailability depends on homeostasis. Homeostasis is maintained in the gastrointestinal system through the absorption of exogenous $\mathrm{Zn}$, and the secretion and excretion of $\mathrm{Zn}$ endogenously ${ }^{50}$. Imbalanced diet, such as food with high-phytate composition (e.g., grains and legumes $)^{51}$ and the presence of certain intestinal microbes ${ }^{52}$ are two examples of factors that can interfere with the effectiveness of $\mathrm{Zn}$ homeostasis. This decreases the amount of $\mathrm{Zn}$ in the body even with excessive red meat intake. Low $\mathrm{Zn}$ levels reduce antioxidant responses for neutralising oxidative stress ${ }^{53}$. Also, the carcinogenic mechanisms of red meat content ${ }^{54}$ can double CRC risk.

Cooking with utensils made from Al or wrapping food in $\mathrm{Al}$ foil can cause $\mathrm{Al}$ leaching into food ${ }^{55}$. Turhan ${ }^{56}$ showed that $\mathrm{Al}$ content was increased by $89-378 \%$ if red meat was cooked and wrapped with Al foil. Marinating meat with a mixture of citric acid and lactic acid and wrapping it with $\mathrm{Al}$ foil can further enhance the $\mathrm{Al}$ content of the meat through leaching ${ }^{57}$. Red meat also has high quantities of Co compared to white meat ${ }^{58}$. The increased Co in red meat can occur through the provision of foods containing high quantities of Co, such as alfalfa seeds or linseed (animal food $)^{59}$. Consequently, excessive red meat consumption indirectly increases $\mathrm{Al}$ and Co levels in the human body. The combination of red meat intake with high $\mathrm{Al}$ or Co levels stimulates carcinogenic mechanisms in CRC formation ${ }^{60,61}$.

We also showed that the interaction between low intake of white meat $(<50 \mathrm{~g} / \mathrm{day})$ and low $\mathrm{Zn}$ levels contributed to higher CRC risk. Unbalanced diets ${ }^{51}$ and the presence of certain intestinal microbes ${ }^{52}$ can cause decreased $\mathrm{Zn}$ levels due to disturbance of $\mathrm{Zn}$ homeostasis. White meat does not produce carcinogens as compared to red meat, but as a result of low $\mathrm{Zn}$ levels, oxidative stress remains uncontrolled ${ }^{62}$, increasing CRC risk.

The factor of obesity combined with low Zn levels or high Co levels also increases CRC risk. Zn levels decrease with increased body mass index ${ }^{63}$. Adipose tissue causes systemic changes in the human body, including altering the levels of insulin, insulin-like growth factor-1, leptin, adiponectin, steroids, and cytokines ${ }^{64}$. This can interfere with $\mathrm{Zn}$ homeostasis and cause $\mathrm{Zn}$ deficiency ${ }^{65}$. In addition, lower levels of a $\mathrm{Zn}$ transporter gene, ZIP14 (SLC39a15), have been reported in obese individuals ${ }^{66}$ and result in Zn reduction in the body ${ }^{67}$. Obesityinduced endocrine changes and gene expression cause low $\mathrm{Zn}$ levels. Thus, it can increase oxidative stress and DNA damage $e^{30,68,69}$, which further contribute to CRC formation. However, the association between obesity and Co levels remains unknown ${ }^{70}$, as does its relation to the mechanism of disease.

CRC RPM. We developed RPMs for CRC based on TEs and environmental risk factors. The model was tested on three groups of patients: high-risk (CRC), moderate-risk (ASX CRC), and low-risk (non-CRC). Early in the CRC RPM development, the addition of environmental risk factors to the TEs increased the accuracy of the CRC RPM. However, the accuracy decreased when tested on the ASX CRC group. This may have been due to an inaccuracy of the environmental risk factors information, which relied heavily on the patient's memory. Hence, the environmental risk factor information obtained is more likely to be biased ${ }^{71}$ than the quantitative measurement of TEs in the patient's blood.

The 14-TE panel (Li, Be, Al, Co, Cu, Zn, As, Se, Cd, Rb, Ba, Hg, Tl, $\mathrm{Pb}$ ) could predict high and low CRC risk but was less precise for the moderate risk group. The development of a new CRC RPM using a 24-TE panel (Ag, $\mathrm{Al}$, As, Ba, Be, Cd, Co, Cr, Cs, Cu, Ga, Li, Mg, Mn, Ni, Pb, Rb, Se, Sr, Tl, U, V, Zn, Hg) increased the value of each performance parameter, especially accuracy. This enabled CRC risk assessment to be classified into three categories, i.e., high, medium, and low. This risk stratification method is useful for early detection of patients with high CRC risk ${ }^{72}$. Hence, colonoscopy and tissue biopsy for determining CRC diagnosis may be prioritized to high-risk individuals first, followed by moderate-risk individuals. Early detection of CRC can be performed through this predictive model even if the patient does not show any clinical symptoms of CRC.

To date, there is no CRC RPM using TEs. However, previous studies have shown that TEs can be used to predict the risk of other cancers and diseases. For example, Guo et al. ${ }^{73}$ used a panel of $10 \mathrm{TEs}$ from hair specimens ( $\mathrm{Mg}, \mathrm{P}, \mathrm{K}, \mathrm{Ca}, \mathrm{Cr}, \mathrm{Mn}, \mathrm{Fe}, \mathrm{Cu}, \mathrm{Zn}, \mathrm{Se}$ ) to predict prostate cancer with $95.8 \%$ accuracy. In addition, demographic, clinical, and trace elements have been incorporated for predicting Parkinson's disease ${ }^{74,75}$. This demonstrates the 
importance of knowledge of the TEs in the human body for use as a predictor of CRC risk. The futher validation may needs from other source population before CRC RPM can be performed in the community.

The main study strength are the novelity of the findings related to TE and less invasive biomarker contribution for early detection of CRC. However, futher validation needs to be done for a more accurate and sensitive results. Information bias is an avoidable situation as we mainly depends on self-reported information. We try to reduce the bias by confirming the self-reported information with family members.

In conclusion, public awareness of healthy and balanced nutrition needs to be improved. Increased awareness of environmental risk factors in the community can reduce the risk of CRC. In Malaysia, various awareness programs have been organised therefore including CRC screening. We would like to recommend the 24-TE panel developed in this study as a screening test for individual stratification with different levels of CRC risk, i.e., high, moderate, or low risk. High-risk individuals should take priority in colonoscopy and tissue biopsy procedures for determining CRC diagnosis, followed by moderate- and low-risk individuals.

\section{Materials and methods}

Participants. Discovery Phase. All participants were newly diagnosed CRC patients from the Universiti Kebangsaan Malaysia (UKM) Medical Centre, Malaysia. Patients were excluded if they had more than one cancer, history or finding of polyps, inflammatory bowel disease (IBD) during colonoscopy, and history of toxic exposure during work. We enrolled 102 patients with CRC and 102 patients without CRC. The participants were interviewed to obtain information on environmental risk factors and underwent blood-taking for TE analysis after histopathology result confirm CRC or not.

Validation phase. All participants from The Malaysian Cohort (TMC) ${ }^{76}$ who are diagnosed with CRC during follow up were included as asymptomatic (ASX) CRC. Initial recruitment started in April 2006 through to the end of September 2012. The information on CRC diagnosis was based on self-reporting during follow-up or from mortality data from the Malaysian National Registration Department. Based on information obtained until June 2017, 85 ASX CRC cases were included in this study.

All participants accepted the terms of the study and provided written informed consent. The study was approved by the UKM Medical Research Ethical Committee (FF-2015-380) as following by the guidelines set out in the Declaration of Helsinki.

Environmental risk factors. All participants completed a set of questionnaires adapted from TMC study, which consisted of information on demographics, socioeconomic status, family history of cancer, comorbidity, smoking status, alcohol consumption, diet intake, body mass index, and physical activity. Diet intake and physical activity were assessed using the food frequency questionnaire and International Physical Activity Questionnaire-Malaysia (IPAQ-M), respectively ${ }^{77}$. The information gather are self-reported and the interview were done by several enumerator. A training session on questionnaire was conducted to minimise the potential interview bias. For the validation phase, the information was extracted from the TMC database.

Quantification of trace elements. Fasting blood was processed to obtain the serum and stored at $-80^{\circ} \mathrm{C}$ until analysis. Samples were pre-treated with acid digestion. The multi-element analysis of 25 TEs (lithium [Li], beryllium [Be], magnesium [Mg], aluminum [Al], vanadium [V], chromium [Cr], manganese [Mn], iron [Fe], cobalt [Co], Ni, copper [Cu], Zn, gallium [Ga], arsenic [As], selenium [Se], rubidium [Rb], strontium [Sr], silver $[\mathrm{Ag}]$, cadmium [Cd], cesium [Cs], barium [Ba], mercury [Hg], thallium [Tl], lead [Pb], uranium [U]) was performed using an Agilent 7700 inductively coupled plasma mass spectrometer (ICP-MS) ${ }^{78}$.

Statistical analysis. Statistical analyses were performed using STATA/SE 13.0, SPSS Modeler version 18, and MetaboAnalyst 4.0. The normality distributions of quantitative data such as TE levels were checked by histogram and the Kolmogorov-Smirnov test. The 25 TEs between the CRC, non-CRC, and ASX CRC samples were compared using the independent $t$-test or analysis of variance for data with a normal distribution; the Mann-Whitney U or Kruskal-Wallis tests were used for data with non-normal distribution. The inter-relationship between each pair of TEs was investigated using Pearson correlation analysis. The distribution pattern of circulating TEs was plotted based on principal component analysis (PCA) and cluster analysis (CA). The best cut-off value for CRC was determined using receiver operating curve (ROC) analysis and the Youden index. The significance level was established at $p<0.05$.

Risk Prediction Model for CRC. The Risk Prediction Model (RPM) was developed based on machine learning (ML) algorithms. First, in the CRC RPM for discovery phase, the data were divided into two sets by the partition node of SPSS Modeler for developing a prediction model using three common ML algorithms: logistic regression (LR), support vector machine (SVM), and artificial neural network (ANN). Of the overall data, 80\% $(n=159)$ were used for model development; the remaining $20 \%(n=40)$ were used for model testing. The CRC RPM was validated among the ASX CRC cases $(n=85)$. Next, an improved CRC RPM with the inclusion of ASX $\mathrm{CRC}$ was developed using the same three ML algorithms. The data were divided into three sets: model development, 60\% $(n=168)$; model testing, 20\% $(n=52)$; and model validation, $20 \%(n=69)$.

The independent variables data consisted of different units and therefore required data normalisation. The normalisation was scaled within the range of $0-1^{79}$. This scaling is suitable for improving the accuracy of numeric computation by the ML algorithms. Accuracy (the percentage of testing data correctly predicted by the model), sensitivity (the proportion of patients with CRC), specificity (the proportion of patients without CRC correctly 
identified by the model), positive predictive value (PPV), negative predictive value (NPV), and area under the curve (AUC) were used for measuring the performance of the prediction models. Ten-fold cross-validation was used to measure the unbiased estimate of the three prediction models for comparing their performance.

\section{Data availability}

All data generated or analysed during this study are included in this published article (and its Supplementary Information files).

Received: 7 April 2020; Accepted: 20 October 2020

Published online: 29 October 2020

\section{References}

1. Ferlay, J. et al. Cancer incidence and mortality worldwide: Sources, methods and major patterns in GLOBOCAN 2012. Int. J. Cancer 136, 359-386 (2015).

2. Arnold, M. et al. Global patterns and trends in colorectal cancer incidence and mortality. Gut 1, 1-9 (2016).

3. Ansa, B. E., Coughlin, S. S., Alema-Mensah, E. \& Smith, S. A. Evaluation of Colorectal Cancer Incidence Trends in the United States (2000-2014). J. Clin. Med. 7, 1-12 (2018).

4. Pourhoseingholi, M. A. Increased burden of colorectal cancer in Asia. World J. Gastrointest. Oncol. 4, 68-70 (2012)

5. Ransohoff, D. F. \& Sandler, R. S. Screening for Colorectal Cancer. N. Engl. J. Med. 346, 40-44 (2002).

6. Issa, I. A. \& NouredDine, M. Colorectal cancer screening: an updated review of the available options. World J. Gastroenterol. 23, 5086-5096 (2017).

7. Fukuda, H. et al. Trace elements and cancer. J. Jpn. Med. Assoc. 47, 391-395 (2004).

8. Mulware, S. J. Trace elements and carcinogenicity: a subject in review. 3 Biotech 3, 85-96 (2013).

9. Silvera, S. \& Rohan, T. Trace elements and cancer risk: a review of the epidemiologic evidence. Cancer Causes Control 18(1), 7-27 (2007).

10. Choi, R. et al. Serum trace elements and their associations with cancer patients. Nutrients 11, 1-15 (2019).

11. Kaba, M. et al. Serum levels of trace elements in patients with testicular cancers. Int. Braz. J. Urol. 41, 1101-1107 (2015).

12. Özbey, F. \& Görgülü, M. Survey of trace element and dietetic fiber composition of "Leblebi " which is a local snack food consumed in Turkey. Food Sci. Technol. 36, 351-355 (2016).

13. Wang, Y. et al. Correlations of trace element levels in the diet, blood, urine, and feces in the Chinese Male. Biol. Trace Elem. Res. 145, 127-135 (2012).

14. Oral, E. V. Determination of the Trace Element Levels in Hair of Smokers and Non-Smokers by ICP-MS. J. Turk. Chem. Soc. 3, 367-380 (2016).

15. Yerlikaya, F. H., Toker, A. \& Arıbaş, A. Serum trace elements in obese women with or without diabetes. Indian J. Med. Res. 137, 339-345 (2013)

16. Usher-smith, J. A., Walter, F. M., Emery, J. D., Win, A. K. \& Grif, S. J. Risk prediction models for colorectal cancer : a systematic review. Cancer Prev. Res. 13, 13-15 (2015).

17. Hollins, D. M. et al. Beryllium and lung cancer: a weight of evidence evaluation of the toxicological and epidemiological literature. Crit. Rev. Toxicol. 39, 1-32 (2009).

18. Romanowicz-Makowska, H., Forma, E., Brys, M., Krajewska, W. M. \& Smolarz, B. Concentration of cadmium, nickel and aluminium in female breast cancer. Pol. J. Pathol. 4, 257-261 (2011).

19. Moulin, J. J. et al. Lung cancer risk in hard-metal workers. Am. J. Epidemiol. 148, 241-248 (1998).

20. Su, Y. et al. Urinary rubidium in breast cancers. Clin. Chim. Acta 412, 2305-2309 (2011).

21. Tsuji, J. S., Alexander, D. D., Perez, V. \& Mink, P. J. Arsenic exposure and bladder cancer: Quantitative assessment of studies in human populations to detect risks at low doses. Toxicology 317, 17-30 (2014).

22. Blaurock-Busch, E. et al. Comparing the metal concentration in the hair of cancer patients and healthy people living in the Malwa region of Punjab India. Clin. Med. Insights Oncol. 8, 1-13 (2014).

23. Sá, I., Semedo, M. \& Cunha, M. E. Kidney cancer. Heavy metals as a risk factor. Porto Biomed. J. 1, 25-28 (2016).

24. Mardanshahi, A. S. M. A. \& Shokrzadeh, M. The comparison of lead and zinc plasma levels in breast cancer patients with standard values. Front. Biomed. Technol. 4, 38-41 (2017).

25. Lin, J. H. \& Giovannucci, E. Environmental exposure and tumor heterogeneity in colorectal cancer risk and outcomes. Curr. Colorectal Cancer Rep. 10, 94-104 (2014).

26. Wu, X., Tang, J. \& Xie, M. Serum and hair zinc levels in breast cancer: a meta-analysis. Sci. Rep. 5, 1-8 (2015).

27. Lubiński, J. et al. Serum selenium levels and the risk of progression of laryngeal cancer. PLoS ONE 13, 1-11 (2018).

28. McElroy, J. A., Kruse, R. L., Guthrie, J., Gangnon, R. E. \& Robertson, J. D. Cadmium exposure and endometrial cancer risk: a large midwestern US population-based case-control study. PLoS ONE 12, 1-15 (2017).

29. Wrobel, J. K., Power, R. \& Toborek, M. Biological activity of selenium: revisited. IUBMB Life 68, 97-105 (2016).

30. Marreiro, D. et al. Zinc and oxidative stress: current mechanisms. Antioxidants 6, 24 (2017).

31. Banerjee, A. et al. A zinc Schiff base complex inhibits cancer progression both in vivo and in vitro by inducing apoptosis. Environ. Toxicol. Pharmacol. 56, 383-392 (2017).

32. Gupta, S. \& Shukla, V. Serum and tissue trace elements in colorectal cancer. J. Surg. Oncol. 52, 172-175 (1993).

33. Klimczak, M. et al. Concentrations of cadmium and selected essential elements in malignant large intestine tissue. Prz Gastroenterol 11, 24-29 (2016)

34. IARC. Cadmium and cadmium compounds. 1-26 (IARC Publications, 2013).

35. Waalkes, M. P. Cadmium carcinogenesis. Mutat. Res. 533, 107-120 (2003).

36. Milde, D., Novák, O. \& Stuzka, V. Serum levels of selenium, manganese, copper, and iron in colorectal cancer patients. Biol. Trace Elem. Res. 79, 107-114 (2001).

37. Iv, A. D. et al. Copper-Zinc ratio and nutritional status in colorectal cancer patients during the perioperative period 1. Acta Cir. Bras. 31, 24-28 (2016).

38. Khoshdel, Z. et al. Serum Copper and Zinc Levels Among Iranian Colorectal Cancer Patients. Biol. Trace Elem. Res. 170, 294-299 (2016).

39. Tchounwou, P. B., Yedjou, C. G., Patlolla, A. K. \& Sutton, D. J. Molecular, Clinical and Environmental. Toxicology 101, 1-30 (2012).

40. Feng, J.-F. et al. Serum total oxidant/antioxidant status and trace element levels in breast cancer patients. Int. J. Clin. Oncol. 17, 575-583 (2012).

41. Bornhorst, J., Kipp, A. P., Haase, H., Meyer, S. \& Schwerdtle, T. The crux of inept biomarkers for risks and benefits of trace elements. TrAC Trends Anal. Chem. 104, 183-190 (2018).

42. Mohamed, M., El-Deeb, K., El-Sheredy, H. G., Mohammed, A. F. \& El-Deeb, M. M. K. The Role of serum trace elements and oxidative stress in Egyptian breast cancer patients. Adv. Breast Cancer Res. 5, 37-47 (2016). 
43. Ali, D. H., Elsheikh, M. A., Khalid, M. A. \& Momen, A. Trace elements in scalp hair and fingernails as biomarkers in clinical studies. J. Heal. Spec. 3, 28 (2015).

44. Zaichick, V. \& Zaichick, S. The content of silver, cobalt, chromium, iron, mercury, rubidium, antimony, selenium, and zinc in malignant giant cell tumor of bone. iMedPub J. 3(4), 1-9 (2015).

45. Stepien, M. et al. Pre-diagnostic copper and zinc biomarkers and colorectal cancer risk in the European Prospective Investigation into Cancer and Nutrition cohort. Carcinogenesis 38(7), 699-707 (2017).

46. ATSDR. ToxGuide for Beryllium. https://www.atsdr.cdc.gov/toxguides/toxguide-4 (2002).

47. ATSDR. ToxGuide for Zinc. https://www.atsdr.cdc.gov/toxguides/toxguide-60 (2005)

48. Unal, I. Defining an optimal cut-point value in ROC analysis: An alternative approach. Comput. Math. Methods Med. 2017, 1-14 (2017).

49. Derbyshire, E. Associations between red meat intakes and the micronutrient intake and status of UK females: a secondary analysis of the UK national diet and nutrition survey. Nutrients 9, 1-11 (2017).

50. Krebs, N. F. Overview of zinc absorption and excretion in the human gastrointestinal tract. J. Nutr. 130, 1374-1377 (2000).

51. Bel-Serrat, S. et al. Factors that affect zinc bioavailability and losses in adult and elderly populations. Nutr. Rev. 72, 334-352 (2014).

52. Gielda, L. \& Dirita, V. Zinc competition among the intestinal zinc competition among the intestinal microbiota. MBio 3, 1-7 (2015).

53. Jarosz, M., Olbert, M., Wyszogrodzka, G., Młyniec, K. \& Librowski, T. Antioxidant and anti-inflammatory effects of zinc Zincdependent NF- $\mathrm{KB}$ signaling. Inflammopharmacology 25, 11-24 (2017).

54. Demeyer, D., Mertens, B., De Smet, S. \& Ulens, M. Mechanisms linking colorectal cancer to the consumption of (processed) red meat: a review. Crit. Rev. Food Sci. Nutr. 56, 2747-2766 (2016).

55. Fekete, V., Deconinck, E., Bolle, F. \& Van Loco, J. Modelling aluminium leaching into food from different foodware materials with multi-level factorial design of experiments. Food Addit. Contam. Part A 29, 1322-1333 (2012).

56. Turhan, S. Aluminium contents in baked meats wrapped in aluminium foil. Meat Sci. 74, 644-647 (2006).

57. Jabeen, S., Ali, B., Khan, M. A., Khan, M. B. \& Hasan, S. A. Aluminum intoxication through leaching in food preparation. Alexandria Sci. Exch. J. 37, 618-626 (2016).

58. Hassan, A. A., Rylander, C., Sandanger, T. M. \& Brustad, M. Copper, Cobalt and Chromium in Meat, Liver, Tallow and Bone Marrow from Semi-domesticated Reindeer ( Rangifer tarandus tarandus L. ) in Northern Norway. Food Public Heal. 3, 154-160 (2013).

59. European Food Safety Authority (EFSA). Scientific Opinion on the use of cobalt compounds as additives in animal nutrition 1. Eur. Food Saf. J. 7, 1-45 (2009).

60. Chiavarini, M., Bertarelli, G., Minelli, L. \& Fabiani, R. Dietary intake of meat cooking-related mutagens (HCAs) and risk of colorectal adenoma and cancer: a systematic review and meta-analysis. Nutrients $9,5-70$ (2017).

61. Klotz, K. et al. The health effects of aluminum exposure. Dtsch. Arztebl. Int. 114, 653-660 (2017).

62. Abid, Z., Cross, A. J. \& Sinha, R. Meat, dairy, and cancer. Am. J. Clin. Nutr. 100, 386S-S393 (2014).

63. Woodhouse, L., Adams, S., Keim, N., Van Loan, M. \& Zunino, S. Plasma Zinc Correlations with Markers of Inflammation in Overweight and Obese Adults; a Cross Sectional Phenotyping Study. FASEB J. 29, 2587 (2015).

64. Hopkins, B. D., Goncalves, M. D. \& Cantley, L. C. Obesity and cancer mechanisms: cancer metabolism. J. Clin. Oncol. 34, 4277-4283 (2016).

65. Fukunaka, A. \& Fujitani, Y. Role of zinc homeostasis in the pathogenesis of diabetes and obesity. Int. J. Mol. Sci. 19, 1-14 (2018).

66. Maxel, T. et al. Gene expression of the zinc transporter ZIP14 (SLC39a14) is affected by weight loss and metabolic status and associates with PPAR $\gamma$ in human adipose tissue and 3T3-L1 pre-adipocytes. BMC Obes. 2, 1-11 (2015).

67. Franklin, R. B., Levy, B. A. \& Costello, L. C. ZIP14 zinc transporter downregulation and zinc depletion in the development and progression of hepatocellular cancer. J Gastrointest. Cancer 43, 249-257 (2013).

68. Cai, G. et al. The effects of cobalt on the development, oxidative stress, and apoptosis in zebrafish embryos. Biol. Trace Elem. Res. 150, 200-207 (2012).

69. Kumar, V. \& Gill, K. D. Oxidative stress and mitochondrial dysfunction in aluminium neurotoxicity and its amelioration: a review. Neurotoxicology 41, 154-166 (2014).

70. Karatela, S. \& Ward, N. I. Trace elements and human obesity: An overview. Manipal Jpournal Nurs. Heal. Sci. 2, 50-59 (2016).

71. Kesmodel, U. S. Information bias in epidemiological studies with a special focus on obstetrics and gynecology. Acta Obstet. Gynecol. Scand. 97, 417-423 (2018).

72. Preen, D. B. et al. Optimizing patient risk stratification for colonoscopy screening and surveillance of colorectal cancer: the role for linked data. Front. Public Heal https://doi.org/10.3389/fpubh.2017.00234 (2017)

73. Guo, J. et al. Prediction of prostate cancer using hair trace element concentration and support vector machine method. Biol. Trace Elem. Res. 116, 257-271 (2007)

74. Sanyal, J. et al. Metallomic Biomarkers in Cerebrospinal fluid and Serum in patients with Parkinson's disease in Indian population. Nat. Publ. Gr. https://doi.org/10.1038/srep35097 (2016).

75. Zhao, H.-W. et al. Assessing plasma levels of selenium, copper, iron and zinc in patients of parkinson's disease. PLoS ONE 8, e83060 (2013).

76. Jamal, R. et al. Cohort profile: the Malaysian cohort (TMC) project: a prospective study of non-communicable diseases in a multiethnic population. Int. J. Epidemiol. 44, 423-431 (2015).

77. Shamsuddin, N., Koon, P. B., Zulkifli, S., Zakaria, S. \& Noor, M. I. Reliability and validity of malay language version of international physical activity questionnaire (IPAQ-M) among the Malaysian Cohort Participants. Int. J. Public Heal. Res. 5, 643-653 (2015).

78. Nawi, A. M., Chin, S. \& Jamal, R. Simultaneous analysis of 25 trace elements in micro volume of human serum by inductively coupled plasma mass spectrometry. Pract. Lab. Med. 18, 1-10 (2020).

79. Kotsiantis, S. B., Kanellopoulos, D. \& Pintelas, P. E. Data preprocessing for supervised learning. Int. J. Comput. Sci. 1, 111-117 (2006).

\section{Acknowledgements}

We thank the UKM Medical Centre endoscopy team for their assistance during sample collection. This work was jointly supported by the Faculty of Medicine, Universiti Kebangsaan Malaysia Medical Centre (FF-2015-380) and Ministry of Education, Malaysia (KPT-PDE 48).

\section{Author contributions}

Study concept and design (A.M.N., S.F.C. and R.J.); acquisition of data (A.M.N., S.F.C., and L.M); analysis and interpretation of data (A.M.N. and S.F.C. ); statistical analysis (A.M.N.and S.F.C. ) drafting of the manuscript (A.M.N., S.F.C. and R.J.). 


\section{Competing interests}

The authors declare no competing interests.

\section{Additional information}

Supplementary information is available for this paper at https://doi.org/10.1038/s41598-020-75760-9.

Correspondence and requests for materials should be addressed to A.M.N. or R.J.

Reprints and permissions information is available at www.nature.com/reprints.

Publisher's note Springer Nature remains neutral with regard to jurisdictional claims in published maps and institutional affiliations.

Open Access This article is licensed under a Creative Commons Attribution 4.0 International License, which permits use, sharing, adaptation, distribution and reproduction in any medium or format, as long as you give appropriate credit to the original author(s) and the source, provide a link to the Creative Commons licence, and indicate if changes were made. The images or other third party material in this article are included in the article's Creative Commons licence, unless indicated otherwise in a credit line to the material. If material is not included in the article's Creative Commons licence and your intended use is not permitted by statutory regulation or exceeds the permitted use, you will need to obtain permission directly from the copyright holder. To view a copy of this licence, visit http://creativecommons.org/licenses/by/4.0/.

(C) The Author(s) 2020 